\title{
REVIEW
}

Open Access

\section{Male and undernourished children were at high risk of anemia in Ethiopia: a systematic review and meta-analysis}

Mulugeta Melku ${ }^{1 *+}$, Wubet Worku Takele², Degefaye Zelalem Anlay², Daniale Tekelia Ekubagewargies², Zegeye Getaneh ${ }^{1}$, Molla Abebe ${ }^{3}$ and Zegeye Abebe ${ }^{4 \dagger}$

\begin{abstract}
Background: Anemia is one of the global public health problems affecting more than one-third of the world population. It has been strongly associated with limited psychomotor development; and poor growth and performance in cognitive, social, and emotional function in children. Despite published data revealed that anemia is a public health problem among children in Ethiopia, there is no a pooled national estimate on the prevalence and associated risk factors of anemia.
\end{abstract}

Methods: Published articles until December 31, 2017, were searched using comprehensive search strings through PubMed/Medline, EMBASE, SCOPUS, HINARI, Web of Science, Google Scholar and Google. Reference probing of published articles and hand searching were employed for grey literature. Two groups of review authors independently appraised the studies for eligibility and extracted the data. The quality of articles was assessed using Joana Brigg's institute critical appraisal checklist for prevalence and analytical studies. The pooled estimates were determined using random effect model. Heterogeneity between the included studies was assessed using the $I^{2}$ statistics. Subgroup analysis was employed in the evidence of heterogeneity. Publication bias was assessed by visual inspection of the funnel plot and Egger's regression test statistic.

Results: Of the total 871 articles retrieved, 34 articles which involved 61,748 children were eligible for meta-analysis. The overall pooled prevalence of anemia using random effect model was 31.14\% (95\% Cl: 24.62, 37.66\%). In subgroup analysis, the pooled prevalence of anemia was higher among preschool-aged children (44.17\%; 95\% Cl: 37.19, 51.15\%) than school-aged children (22.19\%; 95\% Cl: 17.54, 26.83\%). Furthermore, the odds of anemia was higher among children who were male $(\mathrm{OR}=1.11 ; 95 \% \mathrm{Cl}: 1.03,1.19)$, stunted $(\mathrm{OR}=1.95 ; 95 \% \mathrm{Cl}: 1.52,2.51)$, and wasted $(\mathrm{OR}=2.05$; 95\% Cl: 1.36, 3.10).

Conclusion: The pooled prevalence of anemia among children was high, indicating that it had been continuing to be a public health problem. Therefore, there is a need to design a comprehensive prevention and control strategies to reduce its burden.

Keywords: Anemia, Children, Ethiopia, Meta-analysis

\footnotetext{
* Correspondence: mulugeta.melku@gmail.com

${ }^{\dagger}$ Mulugeta Melku and Zegeye Abebe contributed equally to this work.

'Department of Hematology and Immunohematology, School of Biomedical and Laboratory Sciences, College of Medicine and Health Sciences, University of Gondar, P.O. Box 196, Gondar, Ethiopia

Full list of author information is available at the end of the article
}

(c) The Author(s). 2018 Open Access This article is distributed under the terms of the Creative Commons Attribution 4.0 International License (http://creativecommons.org/licenses/by/4.0/), which permits unrestricted use, distribution, and reproduction in any medium, provided you give appropriate credit to the original author(s) and the source, provide a link to the Creative Commons license, and indicate if changes were made. The Creative Commons Public Domain Dedication waiver (http://creativecommons.org/publicdomain/zero/1.0/) applies to the data made available in this article, unless otherwise stated. 


\section{Background}

Anemia is a pathological condition in which the number and size of red blood cells or the hemoglobin concentration of red blood cells drops below an established cutoff value. Anemia can be caused by Iron, Folate, vitamin B12 and vitamin A deficiency, chronic inflammation, parasitic infections, and inherited disorders [1-3]. In developing countries, anemia can also be resulted from a number of causes; but nutritional deficiency particularly iron deficiency is the most common cause.

According to the World Health Organization (WHO) report, anemia is considered to be an indicator of both poor nutrition and health [1]. It is recognized as a major public health problem globally, mostly affecting children, women of childbearing age and pregnancy [4]. The health implication of anemia is numerous. It has a negative impact on mental and physical development, coordination, language development, and scholastic achievement [5-7]. It reduces the immunity which leads to susceptibility to infectious diseases and causes premature death. In addition, the consequences of anemia can be considered from a variety of perspectives, including the detrimental impact on economic and social development [8]. Compared to adults, the effect of anemia on children is horrible as their body is developing. Anemia is the most often hidden deficiency, with a few overt symptoms $[1-3,9]$. Inspite of this, policymakers and health service providers often fail to recognize the massive economic costs and health consequences.

The prevalence of anemia remains high and is of priority area in low-income countries. According to WHO 2015 report, about $43 \%$ of under-five children were anemic, with regional variations of $62.3 \%$ in African, $53.8 \%$ in South-East Asia and 21.9\% in Western Pacific Region [1].

According to the global estimates 2011, the prevalence of anemia among infants and children aged 6-59 months was $40-59.9 \%$ in Ethiopia [1]. Similarly, studies conducted in different parts of Ethiopia indicate that the overall prevalence of anemia ranges $10.7-43.7 \%$ [2, 3, 10-12] among school-age children.

Even though the prevalence of severe to moderate anemia in the last fifteen years has significantly declined in Ethiopia, children and pregnant women are still suffering from the consequences of anemia due to high iron requirements, low intake of iron from foods, and frequent episodes of infection [12, 13]. As many as six in ten under-five children in Ethiopia are anemic. But according to the local conditions, the proportion varies from region to region in the country. For example, the highest level of childhood anemia was found in Somali Region (83\%), followed by Afar (75\%) and Dire Dawa (72\%), but the lowest was found in the Amhara Region (42\%) [14].

The government of Ethiopia has been working to end childhood anemia. Accordingly, it endorsed national nutrition and bimanual school deworming programs; developed micronutrient deficiency prevention and control guideline. But studies from different corners of the country show that childhood anemia is still a major public health problem in Ethiopia. In addition, there is no a single national figure about childhood anemia and also inconclusive evidence about factors associated with it. Systematic review and meta-analysis generates concrete evidence in which it may urge policymakers and program managers to design an appropriate intervention to control and minimize the negative consequence of anemia. There is no meta-analysis conducted showing the pooled prevalence of childhood anemia in Ethiopia so far. Therefore, the aim of this review is to estimate the pooled prevalence and identify factors associated with anemia among children in Ethiopia.

\section{Methods \\ Settings}

This systematic review and meta-analysis was conducted in Ethiopian setting. Ethiopia is one of the developing countries located in the horn of Africa having nearly 100 million people with an area of $1,100,000 \mathrm{~km}^{2}$, making it the 27th largest country in the world. The country is working in reduction of maternal and child under-nutrition through implementing different programs and working jointly with international partners.

\section{Design and protocol registration}

This systematic review was designed according to the Preferred Reporting Items for Systematic Reviews and Meta-Analysis Protocols (PRISMA-P 2015 Guidelines) [15]. The protocol has been registered in the PROSPERO, with the registration number of CRD42018088223.

\section{Search strategy}

Relevant articles published until December 31, 2017 were searched in PubMed/Medline, HINARI, SCOPUS, EMBASE and Web of Sciences electronic databases. Grey literature were searched in Google Scholar and Google. The search terms were developed in accordance with the Medical Subject Headings thesaurus using the following terms in combination with free text key terms, "anemia", "iron deficiency anemia", "nutritional anemia", "hemoglobin", "nutritional status", "hematological parameters" "children", "preschool" "adolescent", "determinant factors of anemia", "associated factors of anemia", and "Ethiopia". The above terms were searched by a combination of Boolean operators (AND, OR). Hand searching of articles published in Ethiopian journal of health sciences, Ethiopian Medical Journal, Ethiopian Journal of Health and Development, and Ethiopian Journal of Health and Biomedical Sciences was conducted. Reference lists of retrieved articles were probed to identify any studies that are not retrieved from electronic databases. 


\section{Study selection and quality appraisal}

All articles retrieved through search strategy were imported to EndNote X7 (Thomson Reuters, New York, USA). After excluding duplicated articles, titles/abstracts were independently screened by two groups of review authors: group one (MM, ZA) and group two (DTE, WWT). Differences were resolved through thorough discussion. In case of disagreement between the two groups of review authors, the decision was determined by the third group of review authors (ZG, MA, DZA). For articles deemed to appear relevant during title/abstract screening, the full-text was appraised for inclusion in systematic review and meta-analysis. The quality of articles was assessed using Joana Brigg's institute (JBI) critical appraisal tools for simple prevalence [16] and analytical cross-sectional studies [17] having nine and eight checklist items, respectively. The discrepancies during critical appraisal were solved as a similar manner for title/abstract screening phase.

\section{Outcomes of the study}

The primary outcome of this review was to estimate the pooled prevalence of anemia among children in Ethiopia. The prevalence was calculated by dividing the number of anemic cases for the total number of children. Also, three determinant factors including sex, stunting, and wasting were assessed. Accordingly, the odds of developing anemia among male, stunted, and wasted children were calculated.

\section{Eligibility criteria \\ Inclusion criteria were:}

- Studies published until December 31, 2017

- Studies reported the outcome of interest among children in Ethiopia

- Observational studies like cross-sectional, prospective cohort studies and repeated cross-sectional studies

\section{Exclusion criteria were:}

- Studies conducted in healthcare facilities

- Studies that used visual comparative method (Sahli-hellige method, and MBS hemoglobinometer color scale) and Copper

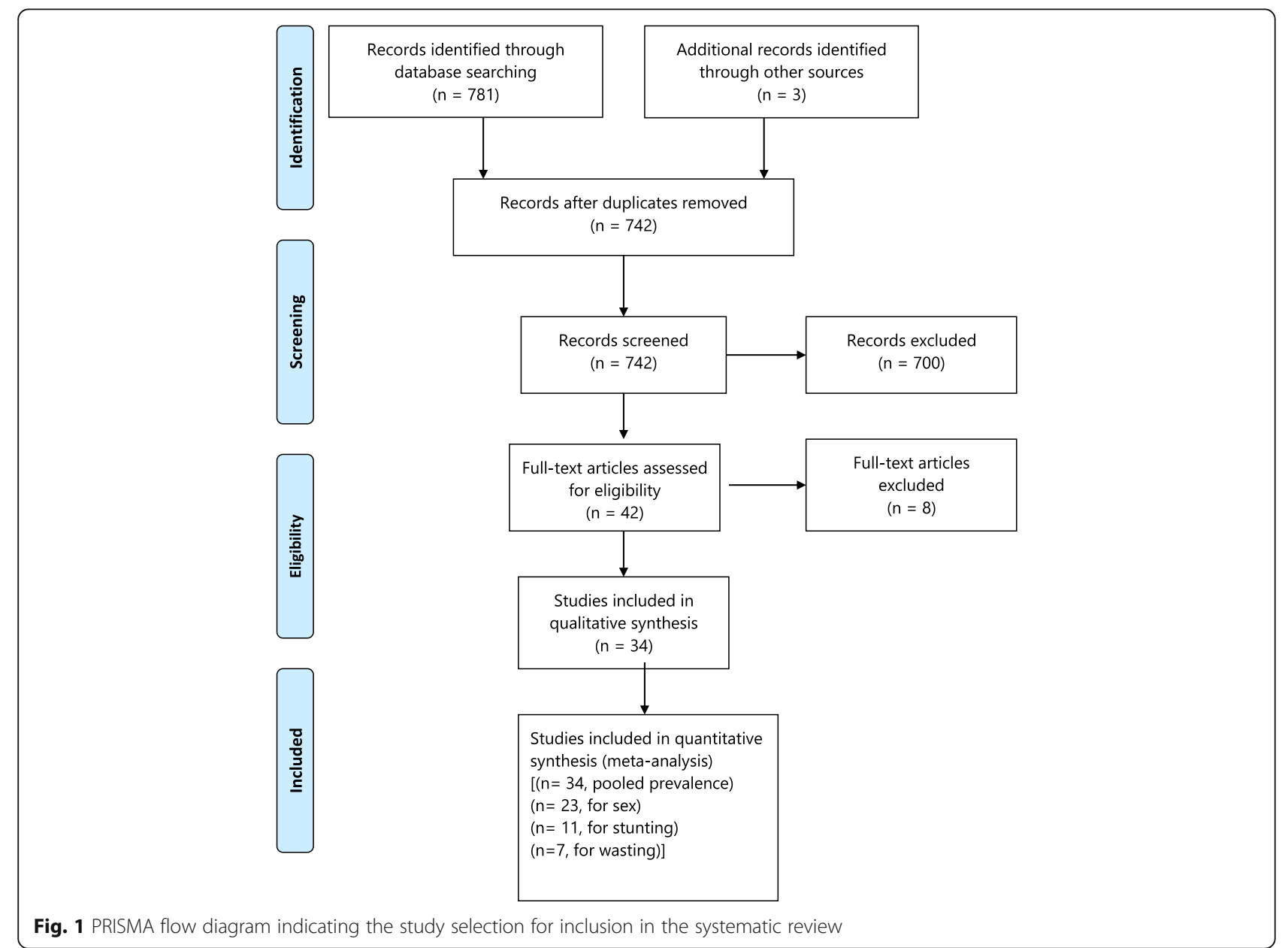


Sulphate densitometer to ascertain the outcome (anemia)

- Studies conducted among children living with HIV/AIDS

\section{Data extraction}

The JBI tool was adopted for data extraction. Information such as the name of first author, year of publication, age group of children, year of study, study area/region, study design, the total number of children, number of anemic case, and number of anemic and non-anemic cases for the reported associated factors were extracted. The data were recorded in Microsoft Excel spreadsheet. When authors found multiple publications from the same dataset, the article that reported the prevalence and associated factors in an extractable form were included. Moreover, for prospective cohort and repeated cross-sectional studies, the baseline data were used for our systematic review and meta-analysis to facilitate comparability of results across studies and to reduce a loss to follow-up bias.

\section{Data analysis}

The data were entered into Microsoft Excel, and then exported to STATA version 14 (Stata Corp LLC, Texas, USA) for analysis. The magnitude of heterogeneity between included studies was quantitatively measured by the index of heterogeneity ( $\mathrm{I}^{2}$ statistics) [18]. The $\mathrm{I}^{2}$ value of 25,50 and $75 \%$ are assumed to represent low, medium and high heterogeneity, respectively. The significance of heterogeneity was determined by a $p$-value of $\mathrm{I}^{2}$ statistics, and a $p$-value $<0.05$ was considered as an evidence of heterogeneity. When the $\mathrm{I}^{2}$ value was greater than $50 \%$, we used Dersimonian and Liard random effect model to determine the pooled estimate [19]. Subgroup analyses were done considering age group and region as a grouping variables. Publication bias was evaluated using the visual funnel plot, and Egger's statistics in the random effect model. Odds ratio with its $95 \%$ confidence was used to estimate the measure of association between anemia and associated factors. The results were presented in text and Forest plot.

$$
\begin{aligned}
& \begin{array}{l|l}
\text { Study } & \\
\text { ES }(95 \% \mathrm{Cl}) & \%
\end{array} \\
& \text { ID } \quad \text { ES }(95 \% \mathrm{Cl}) \quad \text { Weigh } \\
& \text { Mahmud MA et al (2013) } \\
& \text { Tesfaye M et al (2015) } \\
& \text { Getnet A et al (2015) } \\
& \text { Chane } \mathrm{H} \text { et al (Grey) } \\
& \text { Yimam Y et al (2016) } \\
& \text { Reithinger } \mathrm{R} \text { et al (2013) } \\
& \text { Gutema B et al (2014) } \\
& \text { Taye B et al (2015) } \\
& \text { Herrador Z et al (2014) } \\
& \text { Woldie } \mathrm{H} \text { et al (2015) } \\
& \text { Desalegn A et al (2014) } \\
& \text { Gebreegziabiher } \mathrm{G} \text { et al (2014) } \\
& \text { Alelign T et al (2015) } \\
& \text { Mesfin F et al (2015) } \\
& \text { Assefa S et al (2014) } \\
& \text { Deribew A et al (2010) } \\
& \text { Birmeka M et al (2017) } \\
& \text { Engidaye } \mathrm{G} \text { et al (Grey) } \\
& \text { Getaneh Z et al (2017) } \\
& \text { Melku M et al (Grey) } \\
& \text { Muchie KF (2016) } \\
& \text { Guled RA et al (2017) } \\
& \text { Roba KT et al (2017) } \\
& \text { Feleke BE et al (2017) } \\
& \text { Tiku YS et al (2018) } \\
& \text { Birhanu Z et al (2017) } \\
& \text { Grimes JET et al (2017) } \\
& \text { Gari T et al (2017) } \\
& \text { Mekasha A et al (2009) } \\
& \text { Hall A et al (2008) } \\
& \text { Gashu D et al (2016) } \\
& \text { EDHS } 2016 \text { (2017) } \\
& \text { EDHS } 2005 \text { (2006) } \\
& \text { Adish AA et al (1999) } \\
& \text { Overall (I-squared }=99.7 \%, p=0.000) \\
& \text { NOTE: Weights are from random effects analysis } \\
& 10.86(8.20,13.52) \\
& 15.20(11.71,18.68) \\
& \begin{array}{ll}
25.83(21.31,30.35) & 2.92 \\
21.88(18.29,25.46) & 2.94
\end{array} \\
& 21.88(18.29,25.46) \quad 2.94 \\
& 15.14(11.64,18.64) \quad 2.94 \\
& 36.41(35.19,37.62) \quad 2.96 \\
& 23.66(19.24,28.08) \quad 2.92 \\
& 34.78(31.34,38.21) \quad 2.94 \\
& 31.28(28.00,34.57) \quad 2.94 \\
& 66.57(61.61,71.53) \quad 2.91 \\
& 43.69(39.67,47.70) \quad 2.93 \\
& \begin{array}{ll}
37.32(33.35,41.30) & 2.93
\end{array} \\
& 10.68(7.59,13.77) \\
& 27.07(24.99,29.14) \quad 2.95 \\
& 37.62(32.90,42.35) \quad 2.92 \\
& 32.37(30.50,34.23) \\
& 31.32(27.84,34.81) \\
& 28.47(24.22,32.73) \\
& 15.49(12.39,18.59) \\
& 28.57(25.24,31.90) \\
& 50.30(49.18,51.42) \\
& 72.04(67.63,76.46) \\
& 53.70(47.05,60.35) \\
& 7.63(6.56,8.70) \\
& 51.38(46.47,56.28) \\
& 17.30(14.62,19.98) \\
& 23.15(21.78,24.51) \\
& 28.25(26.64,29.87) \\
& 5.83(4.10,7.56) \\
& 9.80(9.12,10.47) \\
& 13.62(10.88,16.36) \\
& 57.00(55.99,58.01) \\
& 54.00(52.48,55.52) \\
& 42.00(39.88,44.12) \\
& 31.14(24.62,37.66)
\end{aligned}
$$

(2)




\section{Results}

\section{Description of studies}

A total of 781 records were retrieved, of which 38 articles were removed due to duplication. Seven hundred articles were also removed as their titles and abstract was irrelevant to the current analysis. The remaining 42 full-text articles were assessed for eligibility based on the pre-set criteria (Fig. 1).

Out of 42 studies, 8 were excluded: 4 studies were duplicated publications [20-23]; 2 studies were difficult to extract the outcome variables [24, 25]; and 2 studies were conducted in healthcare settings [26, 27].

In this review, 29 published studies, 2 demographic and health survey and 3 grey literature, which involved a total of 61,748 study participants, were included. Thirty-three (97.1\%) and $1(2.9 \%)$ of the included studies were cross-sectional, and repeated cross-sectional studies, respectively. Concerning study settings where the studies were conducted, it has been as follows: $26.5 \%$ in Amhara Regional State $([11,12,28-32]$ Engidaye G, Melku M, Yalew A, Getaneh Z, Asrie F, Enawgaw B: Prevalence of anemia and associated factors among preschool-aged-children in Menz Gera Midir district, eastern Amhara,
Ethiopia: a community based cross sectional study, submitted; Melku M, Alene KA, Terefe B, Enawgaw B, Melak T, Biadgo B, et al: Anemia Severity among Children Aged 6-59 Months in Gondar Town, Ethiopia: a communitybased cross-sectional study, submitted); $17.6 \%$ in South Nations and Nationalities Regional State ([33-37]; Chane H: Magnitude of anemia and its contributing factor among school age children in Mihur Aklil district, Gurage zone. Ethiopia, unpublished]) and $20.6 \%$ in Oromia Regional State [2, 3, 13, 38-42]; 8.8\% in Tigray Regional State [43-45]; $17.6 \%$ were national studies $[14,40,46-49]$; and $5.9 \%$ in Somali Regional State [10, 50]. In addition, $2.9 \%$ studies were conducted in Addis Ababa [51]. Of all included studies, about 59.4 and $37.5 \%$ of the studies were conducted among school-aged and preschool-aged children, respectively.

Regarding the association between anemia and sex, 23 studies were included; of which, $76.2 \%$ of the studies exhibited that there is no association between anemia and the sex of the children. Similarly, 11 studies were included to estimate the association between anemia and stunting. Around $82 \%$ of the studies revealed that the odds of anemia was higher among stunted children compared to non-stunted children. Furthermore, 5 studies

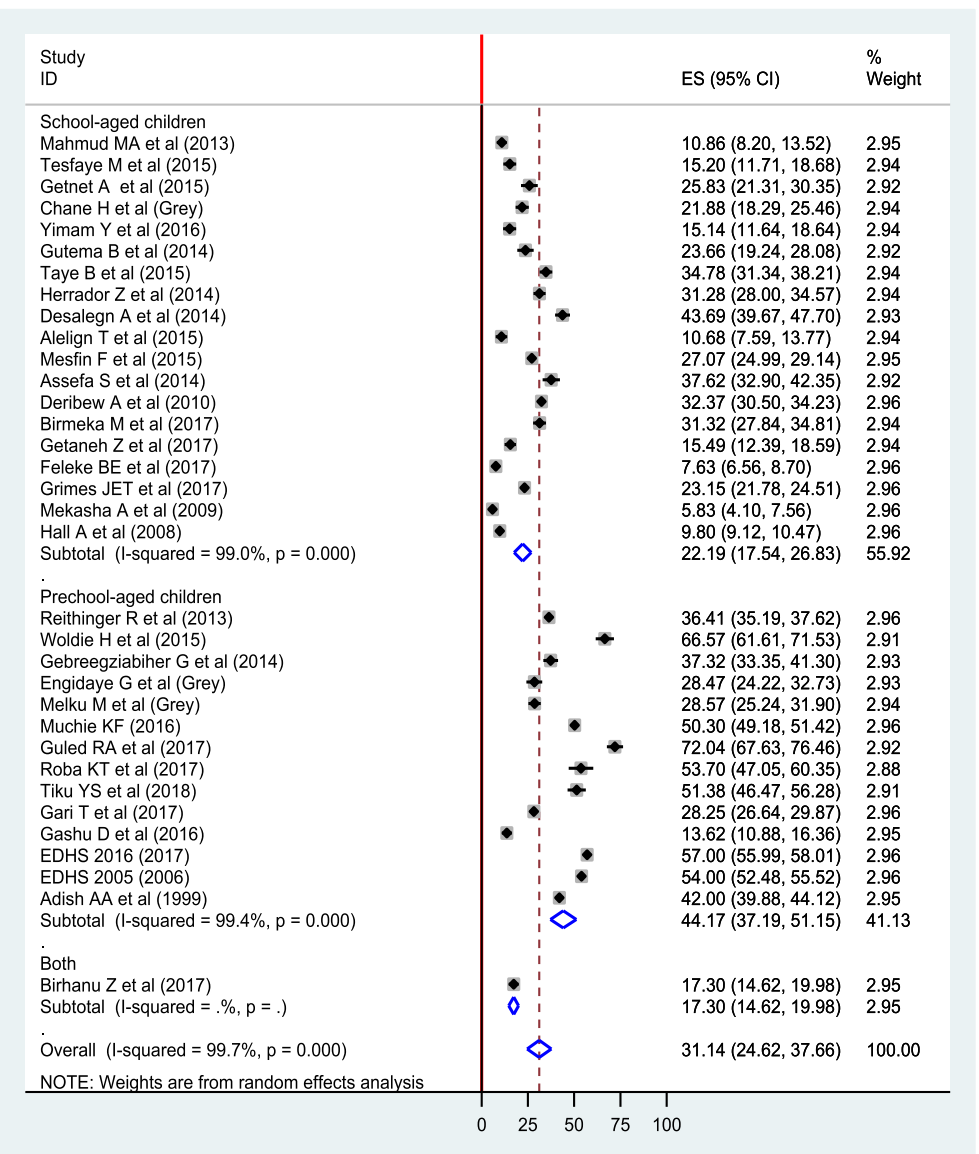

Fig. 3 Forest plot of subgroup analysis of anemia among preschool-aged and school-aged children using random effect model 
reported that the likelihood of being anemic was higher among wasted children compared to their counterparts.

\section{Pooled prevalence of anemia}

The overall pooled prevalence of anemia using random effect model was 31.14\% (95\% CI: 24.62, 37.66\%) (Fig. 2). We used a Funnel plot as well as Egger's test of the intercept to check publication bias. The funnel plot is symmetrical (Additional file 1: Figure S1); and the Egger's test result was 23.29 (95\% CI: 11.32, 35.26, $p=0.387$ ) (Additional file 2: Figure S2), indicating that there is no publication bias. We also assessed heterogeneity of the reported studies using the $\mathrm{I}^{2}$ statistics and it was significant $\left(\mathrm{I}^{2}=99.7 \%, p<0.001\right)$, showing a high level of heterogeneity between the included studies. Subgroup analyses were done by considering age and region as grouping variables. Accordingly, the pooled prevalence of anemia among preschool-aged children was $44.17 \%$ (95\% CI: 37.19, 51.15\%), whereas it $22.19 \%$ (95\% CI: $17.54,26.83 \%$ ) among school-aged children (Fig. 3). In terms of region, the highest and the lowest prevalence was found in Somalia region
(47.85\%) and Addis Ababa (5.83\%), respectively (Fig. 4). In addition, a sensitivity analysis was done and the result showed that there was no a single estimate out of the combined estimate's 95\% confidence interval/range.

\section{Association between anemia, sex, and undernutrition}

In random effect model, the pooled effect size of anemia among males was 1.11 ( $\mathrm{OR}=1.11$; 95\% CI: 1.03, 1.19) times higher compared to females (Fig. 5).

The result showed that nutritional status has a significant association with anemia. Accordingly, higher odds of being anemic was found among stunted children compared to their counterparts $(\mathrm{OR}=1.95 ; 95 \% \mathrm{CI}$ : 1.52 , 2.51) (Fig. 6). On the other hand, wasted children were 2.05 times $(\mathrm{OR}=2.05$; 95\% CI: $1.36,3.10)$ more likely to be anemic compared to non-wasted children (Fig. 7).

\section{Discussion}

Anemia has been a public health problem affecting the low, middle and high-income countries. It has also been significantly associated with negative consequences on health,

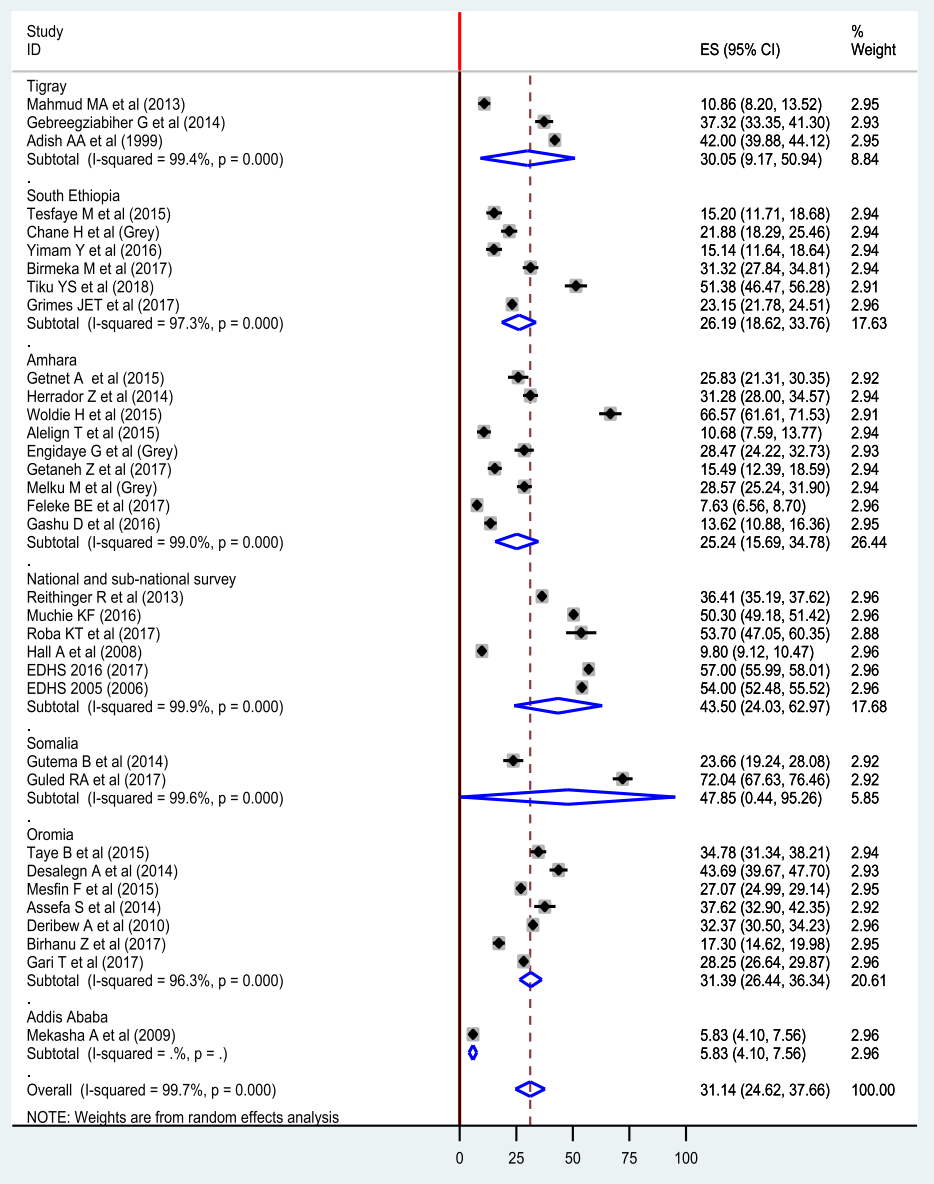

Fig. 4 Forest plot of subgroup analysis of anemia by region using random effect model 


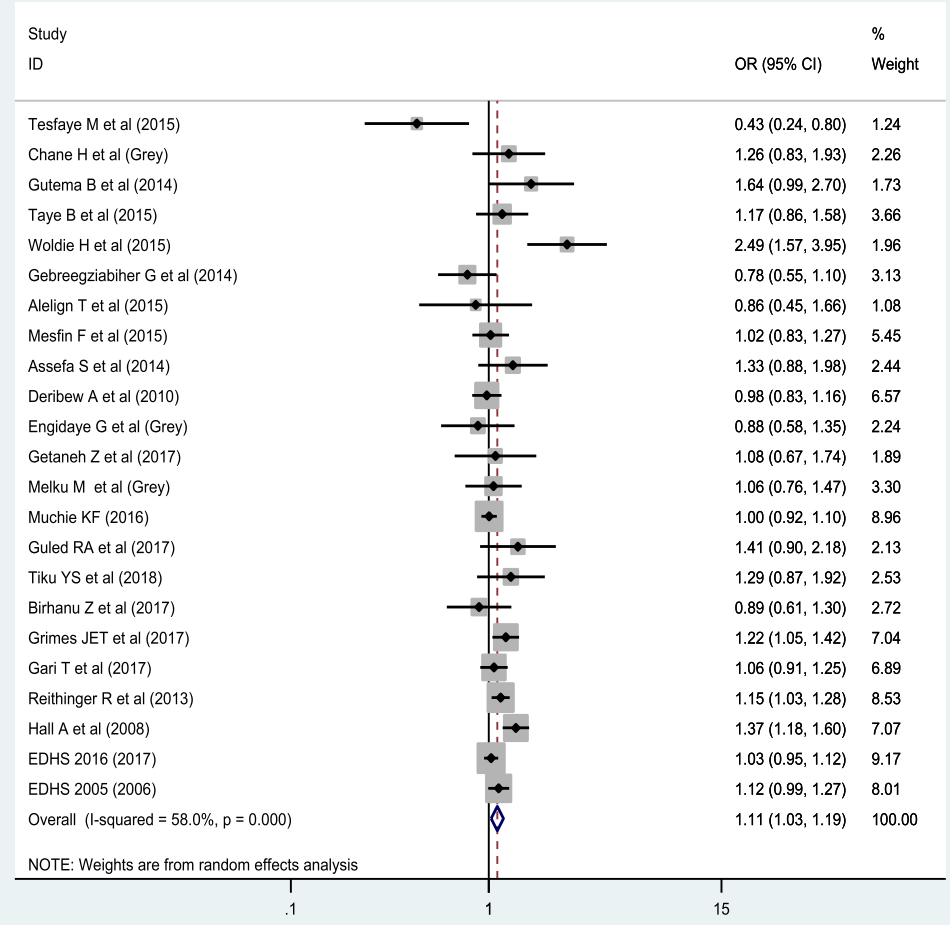

Fig. 5 Forest plot of the association between anemia and male sex using random effect model

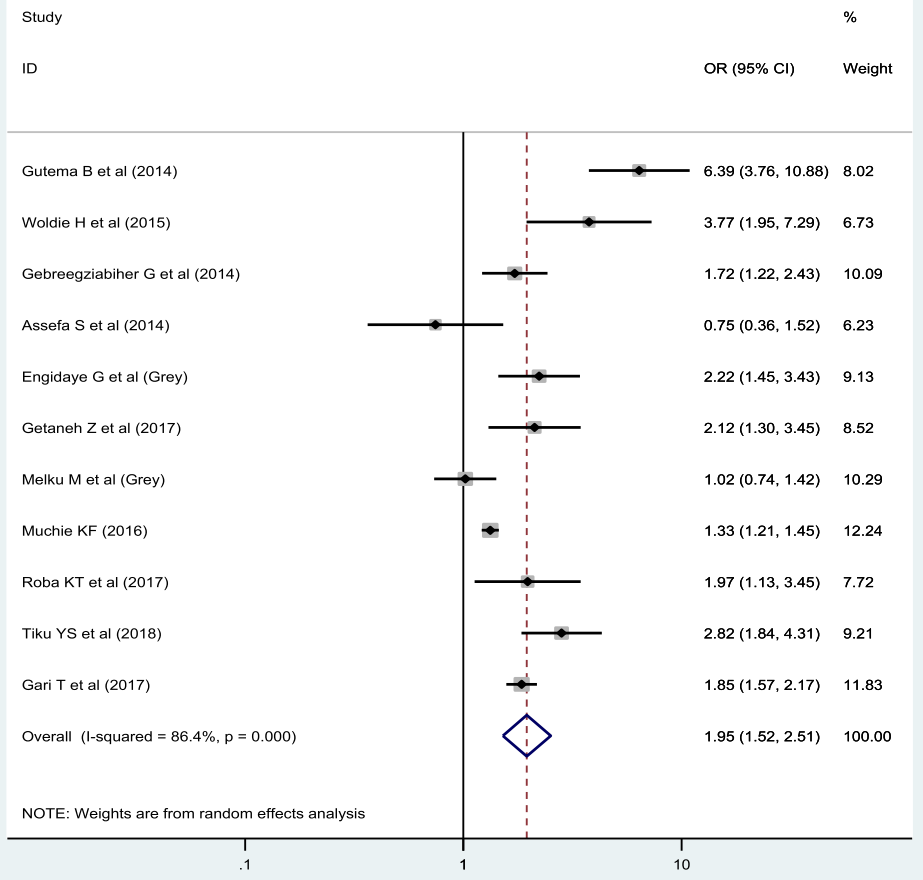

Fig. 6 Forest plot of the association between anemia and stunting using random effect model 


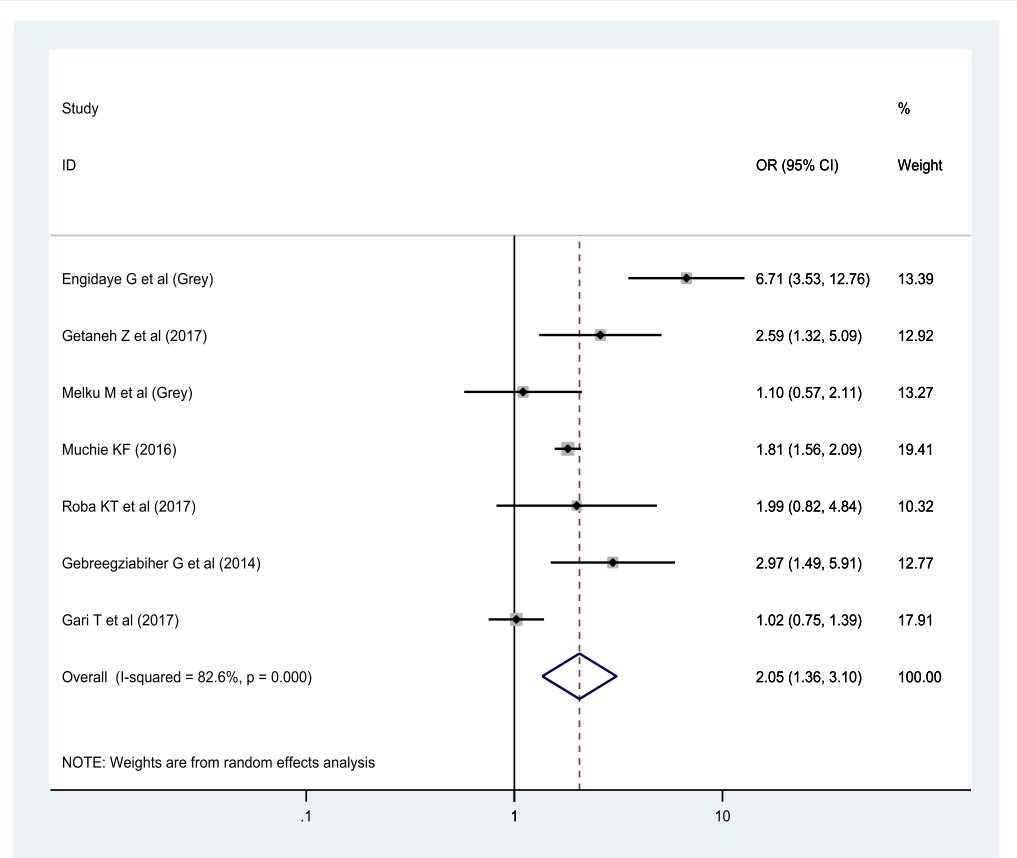

Fig. 7 Forest plot of the association between anemia and wasting using random effect model

social and economic development $[52,53]$. Globally, it is a moderate to a severe public health problem in children. As to the WHO 2015 estimate, the highest prevalence of anemia is found in children, $42.6 \%$ (95\% CI: 37, 47\%) [54]. The consequence of anemia is worse in children as it limits the physical growth [55], metal [56], social [57] as well as the behavioral development [58].

The overall pooled prevalence of anemia was $31.14 \%$ (95\% CI: 24.62, 37.66\%). This implies that anemia is a moderate public health problem among children in Ethiopia [59], which needs to design intervention and control strategies in a comprehensive approach to reduce its burden. The estimated prevalence is consistent with the global age-standardized prevalence of anemia in 2013 (27.0\%) and in 1990 (33.3\%) [60], and global age-unstandardized prevalence in 2010 (32.9\%) [61].

In subgroup analysis, the pooled prevalence of anemia among school-aged children was $22.19 \%$ (95\% CI: 17.54, $26.83 \%$ ), which is lower than pooled estimate among preschool-aged children, 44.17\% (95\% CI: 37.19, 51.15\%). It is reasonable that the magnitude of anemia declines as the age of children advanced. Compared to school-aged children, preschool-aged children have high dietary requirement owing to rapid rate of growth [39] and expansion of blood volume, which lead to nutritional imbalance. Moreover, the biannual school-based deworming program that the government of Ethiopia recently implemented, and water, sanitation, and hygiene (WASH) program are substantially contributing for low parasitic infestation [37,
$59,62]$, and ultimately reduced the prevalence of anemia among school-aged children.

In random effect model, the pooled effect size of anemia among male children is higher than female children (OR = 1.11; 95\% CI: 1.03. 1.19). Consistent with previous studies $[63,64]$, the risk of anemia is high in male than female children. Growth and gonadal hormones are the key role players of growth and development in children, and pre-pubertal and pubertal boys and girls [65]. Despite lower than adults, evidence suggested that the level of testosterone is higher in boys than girls during pre-puberty stage [66], and in early pubertal and pubertal development [67]. Testosterone is a known stimulator of erythropoiesis and enhanced metabolism [68]. High level of testosterone in boys stimulates growth velocity so that boys have high nutritional requirement than girls. Concurrently, undernutrition is a common problem among children in Sub-Saharan countries including Ethiopia [11, 69-71] which may lead to the development of nutritional deficiency anemia, particularly iron deficiency anemia, in boys than girls.

In this meta-analysis, a higher odds of anemia was noted among stunted $(\mathrm{OR}=1.95 ; 95 \% \mathrm{CI}: 1.36,2.51)$ and wasted $(\mathrm{OR}=2.05 ; 95 \% \mathrm{CI}: 1.36,3.10)$ children. Previous literature also supported that stunting [12, 72-74] and wasting [43] are a strong predictors of childhood anemia. In the developing nations, where a diverse supply of foods is limited, macro and micronutrients deficiencies are the common public health problems [75]. As the 
result, stunting and wasting, which are the indicator of chronic and acute malnutrition, respectively, have imposed a great challenge on child health [76]. One of which is anemia that can be resulted from inadequate intake of both macro and micronutrients such as iron, B12 and folate, which are important for the formation of blood cells [77]. Besides, undernutrition impairs the immunity in which children become susceptible to infectious diseases. The situation may cause a loss of nutrients, malabsorption, underutilization of bioavailable nutrients, blood loss and immune-mediated destruction of $\mathrm{RBCs}$, which have been associated with low level of hemoglobin [78].

The review has some limitations. The extent of heterogeneity between included studies was high, which can be attributed to differences in methodology, study period, and geographic location. Moreover, some of the studies did not consider an altitudinal adjustment to define anemia, which may underestimate the burden of anemia among children. Given these limitations, the review was conducted according to the preferred reporting items for systematic review and meta-analysis (PRISMA-P statement) protocol. Besides, a comprehensive searching with no language restriction and the involvement of experts from biomedical, public health and clinical fields improved quality of evidence generated.

\section{Conclusion}

In conclusion, the pooled national prevalence of anemia among children was high. As to the WHO classification of anemia on the basis of public health importance, it is a moderate public health problem among children in Ethiopia. The pooled prevalence was higher among preschool-aged children than school-aged children. Moreover, the likelihood of anemia was higher among male and undernourished children. Therefore, optimizing the nutritional supplementation, improving access to child health care, and sustaining the socio-economic development need to be emphasized to reduce the burden of childhood anemia in Ethiopia.

\section{Additional files}

Additional file 1: Figure S1. Funnel Plot. The Funnel plot showing the pooled estimate of anemia among children in Ethiopia. This is a visual method to see small-study effect or publication bias. (DOC $26 \mathrm{~kb}$ )

Additional file 2: Figure S2. Egger's Plot. A Plot of Egger's test of publication bias for pooled estimate of anemia among children in Ethiopia. Egger's test is a statistical method to test the presence of small-study effect or publication bias on the pooled estimate. (DOC 26 kb)

\section{Authors' contributions}

MM, ZA, WWT: Conceived the design; MM, ZA, ZG, and WWT: developed the search strategy; MM, ZA, ZG, WWT, DTE, DZA, and MA: searched, screened and appraised the studies, and extracted the data; MM, ZA, MA and DZA: Analyzed the data; ZA, MM, ZG, WWT and MA: Involved during the drafting of the manuscript. All authors read and approved the final manuscript for publication.

Ethics approval and consent to participate

Not applicable.

Consent for publication

Not applicable.

\section{Competing interest}

The authors declare that they have no competing interest.

\section{Publisher's Note}

Springer Nature remains neutral with regard to jurisdictional claims in published maps and institutional affiliations.

\section{Author details}

${ }^{1}$ Department of Hematology and Immunohematology, School of Biomedical and Laboratory Sciences, College of Medicine and Health Sciences, University of Gondar, P.O. Box 196, Gondar, Ethiopia. ${ }^{2}$ School of Nursing, College of Medicine and Health Sciences, University of Gondar, Gondar, Ethiopia.

${ }^{3}$ Department of Clinical Chemistry, School of Biomedical and Laboratory Sciences, College of Medicine and Health Sciences, University of Gondar, P.O. Box 196, Gondar, Ethiopia. ${ }^{4}$ Department of Human Nutrition, Institute of Public Health, College of Medicine and Health Sciences, University of Gondar, P.O. Box 196, Gondar, Ethiopia.

Received: 28 February 2018 Accepted: 13 June 2018

Published online: 11 July 2018

\section{References}

1. WHO. The global prevalence of anaemia in 2011. Geneva: World Health Organization; 2015.

2. Assefa S, Mossie A, Hamza L. Prevalence and severity of anemia among school children in Jimma town, Southwest Ethiopia. BMC hematol. 2014;14(1):3.

3. Desalegn A, Mossie A, Gedefaw L. Nutritional iron deficiency anemia: magnitude and its predictors among school age children, Southwest Ethiopia: a community based cross-sectional study. PLoS One. 2014;9(12):e114059.

4. Harika R, Faber M, Samuel F, Mulugeta A, Kimiywe J, Eilander A. Are low intakes and deficiencies in Iron, vitamin a, zinc, and iodine of public health concern in Ethiopian, Kenyan, Nigerian, and south African children and adolescents. Food Nutr Bull. 2017;

5. Walter T. Effect of iron-deficiency anemia on cognitive skills and neuromaturation in infancy and childhood. Food Nutr Bull. 2003;24(4)

6. WHO. Worldwide prevalence of anaemia 1993-2005. Geneva: World Health Organization; 2008.

7. Santos JN, Rates SPM, Lemos SMA, Lamounier JA. Consequences of anemia on language development of children from a public day care center. Rev Paul Pediatr. 2009;27(1):67-73.

8. Plessow R, Arora NK, Brunner B, Tzogiou C, Eichler K, Brügger U, et al. Social costs of iron deficiency anemia in 6-59-month-old children in India. PLoS One. 2015;10(8):e0136581.

9. Kotecha PV. Nutritional anemia in young children with focus on Asia and India. Indian journal of community medicine: official publication of Indian Association of Preventive \& social. Medicine. 2011;36(1):8.

10. Gutema B, Adissu W, Asress Y, Gedefaw L. Anemia and associated factors among school-age children in Filtu town, Somali region, Southeast Ethiopia. BMC hematol. 2014;14(1):13.

11. Alelign T, Degarege A, Erko B. Prevalence and factors associated with undernutrition and anaemia among school children in Durbete town, Northwest Ethiopia. Archives of Public Health. 2015;73:34.

12. Getaneh Z, Enawgaw B, Engidaye G, Seyoum M, Berhane M, Abebe Z, et al. Prevalence of anemia and associated factors among school children in Gondar town public primary schools,Northwest Ethiopia:a school based cross-sectiona Istudy. PLoS One. 2017;12(12):e0190151.

13. Deribew A, Alemseged F, Tessema F, Sena L, Birhanu Z, Zeynudin A, et al. Malaria and under-nutrition: a community based study among under-five children at risk of malaria, south-West Ethiopia. PLoS One. 2010;5(5):e10775.

14. Central Statistical Agency [Ethiopia] and ICF International. Ethiopia Demographic and Health Survey 2011. Addis Ababa, Ethiopia and Calverton. Maryland: Central Statistical Agency and ICF International. p. 2016. 
15. Shamseer L, Moher D, Clarke M, Ghersi D, Liberati A, Petticrew M, et al. Preferred reporting items for systematic review and meta-analysis protocols (PRISMA-P) 2015: elaboration and explanation. BMJ. 2015;350:g7647.

16. Munn Z, Moola S, Lisy K, Riitano D, Tufanaru C. Methodological guidance for systematic reviews of observational epidemiological studies reporting prevalence and incidence data. Int J Evid Based Healthc. 2015;13(3):147-53.

17. JBI. The Joanna Briggs Institute Critical Appraisal tools for use in JBI Systematic Reviews: Checklist for Analytical Cross Sectional Studies 2016. Accessed at: http://joannabriggs.org/research/critical-appraisal-tools.html; accessed date: 21 Jan 2018.

18. Higgins J, Thompson SG. Quantifying heterogeneity in a meta-analysis. Stat Med. 2002:21(11):1539-58.

19. DerSimonian R, Laird N. Meta-analysis in clinical trials. Control Clin Trials. 1986;7(3):177-88.

20. Fentahun K, Gabre-yohannes E. Risk factors of anemia in children aged 6 to 59 months in Ethiopia. J Ethiopian Stat Assoc. 2014;23:17-28.

21. Habte D, Asrat K, Magafu MG, Ali IM, Benti T, Abtew W, et al. Maternal risk factors for childhood Anaemia in Ethiopia. Afr J Reprod Health. 2013;17(3):110-8.

22. Roba KT, O'Connor TP, Belachew T, O'Brien NM. Concurrent iron and zinc deficiencies in lactating mothers and their children 6-23 months of age in two agro-ecological zones of rural Ethiopia. Eur J Nutr. 2016. https://doi.org/ 10.1007/s00394-016-1351-5

23. Gashu D, Stoecker BJ, Bougma K, Adish A, Haki GD, Marquis GS. Stunting, selenium deficiency and anemia are associated with poor cognitive performance in preschool children from rural Ethiopia. Nutr J. 2016;15:38.

24. Degarege A, Animut A, Medhin G, Legesse M, Erko B. The association between multiple intestinal helminth infections and blood group, anaemia and nutritional status in human populations from dore Bafeno, southern Ethiopia. J Helminthol. 2014;88:152-9.

25. Degarege A, Yimam Y, Madhivanan P, Erko B. The relationship between helminth infections and low haemoglobin levels in Ethiopian children with blood type a. J Helminthol. 2016. https://doi.org/10.1017/ S0022149X16000286.

26. Kebede SW, Beyene DA, Meshesha AG, Sinishaw MA. Two thirds of hookworm infected children were anemic at the outpatient department in Jimma Health Center, Jimma, Southwest Ethiopia. Asian Pac J Trop Dis. 2016;6(9):691-4.

27. G/Selassie Y, Tsegaye A, Alemu J, B/Selassie M. Magnitude, Severity and Associated Factors of Anemia among underfive Children attending Hawassa University Teaching and Referral Hospital and Adare Hospital in Hawassa, Southern Ethiopia. 2016.

28. Herrador Z, Sordo L, Gadisa E, Buno A, Go'mez-Rioja R, Iturzaeta JM, et al. micronutrient deficiencies and related factors in school-aged children in Ethiopia: a cross-sectional study in Libo Kemkem and Fogera districts, Amhara regional state. PLoS One. 2014;9(12):e112858.

29. Woldie H, Kebede $Y$, Tariku A. Factors associated with Anemia among children aged 6-23 months attending growth monitoring at Tsitsika health Center,wag-Himra zone, Northeast Ethiopia. J Nutr Metab. 2015; https://doi. org/10.1155/2015/928632

30. Feleke BE, Derbie A, Zenebe Y, Mekonnen D, Hailu T, Tulu B, et al. Burden and determinant factors of Anemia among elementary school children in Northwest Ethiopia: a comparative cross sectional study. Afr, J Infect Dis. 2017;12(1):1-6.

31. Gashu D, Stoecker BJ, Adish A, Haki GD, Bougma K, Marquis GS. Ethiopian pre-school children consuming a predominantly unrefined plant-based diet have low prevalence of iron-deficiency anaemia. Public Health Nutr. 2016;19(10):1834-41.

32. Getnet A, Worku S. The association between major helminth infections (soil-transmitted helminthes and schistosomiasis) and Anemia among school children in Shimbit elementary school, Bahir Dar, Northwest Ethiopia. American Journal of Health Research. 2015;3(2):97-104.

33. Tesfaye M, Yemane T, Adisu W, Asres Y, Gedefaw L. Anemia and iron deficiency among school adolescents: burden, severity, and determinant factors in Southwest Ethiopia. Adolescent health, medicine and therapeutics. 2015;6:189.

34. Yimam $Y$, Degarege $A$, Erko B. Effect of anthelminthic treatment on helminth infection and related anaemia among school-age children in northwestern Ethiopia. BMC Infect Dis. 2016;16(1):613.

35. Birmeka M, Urga K, Petros B. Assessment of Anemia and Iron Status of Primary School children aged 7-19 in Enemore-Ener and Abeshege Districts, Gurage Zone, Ethiopia. EC Nutrition. 2017;10(1):18-25.
36. Tiku YS, Mekonnen TC, Workie SB, Amare E. Does Anaemia have major public health importance in children aged 6-59 months in the Duggina Fanigo District of Wolaita Zone,Southern Ethiopia? Ann Nutr Metab. 2018;72:3-11.

37. Grimes JE, Tadesse G, Mekete K, Wuletaw Y, Gebretsadik A, French MD, et al. School water, sanitation, and hygiene, soil-transmitted helminths, and schistosomes: national mapping in Ethiopia. PLoS Negl Trop Dis. 2016;10(3):e0004515.

38. Mesfin F, Berhane $Y$, Worku A. Anemia among primary school children in eastern Ethiopia. PLoS One. 2015;10(4):e0123615.

39. Taye B, Enquselassie F, Tsegaye A, Amberbir A, Medhin G, Fogarty A, et al. Effect of early and current helicobacter pylori infection on the risk of anaemia in 6.5-year-old Ethiopian children. BMC Infect Dis. 2015; 15(1):270.

40. Roba KT, O'Connor TP, Belachew T, O'Brien NM. Anemia and undernutrition among children aged 6-23 months in two agroecological zones of rural Ethiopia. Pediatric Health, Medicine and Therapeutics. 2017;55(140):131-40.

41. Birhanu Z, Yihdego YY, Emana D, Feyissa D, Kenate S, Kebede E, et al. Relationship between exposure to malaria and haemoglobin level of children 2-9 years old in low malaria transmission settings. Acta Trop. 2017;173:1-10.

42. Gari T, Loha E, Deressa W, Solomon T, Atsbeha H, Assegid M, et al. Anaemia among children in a drought affected community in south-central Ethiopia. PLoSONE.12(3):e0170898. https://doi.org/10.1371/journal. pone.

43. Gebreegziabiher G, Etana B, Niggusie D. Determinants of anemia among children aged 6-59 months living in Kilte Awulaelo Woreda, northern Ethiopia. Anemia. 2014;2014

44. Mahmud MA, Spigt M, Mulugeta Bezabih A, López Pavon I, Dinant G-J, Blanco Velasco R. Risk factors for intestinal parasitosis, anaemia, and malnutrition among school children in Ethiopia. Pathogens and global health. 2013;107(2):58-65.

45. Adish A, Esrey S, Gyorkos T, Johns T. Risk factors for iron deficiency anaemia in preschool children in northern Ethiopia. Public Health Nutr. 1999;2(3):243-52.

46. Reithinger R, Ngondi JM, Graves PM, Hwang J, Getachew A, Jima D. Risk factors for anemia in children under 6 years of age in Ethiopia: analysis of the data from the cross-sectional Malaria Indicator Survey, 2007. Trans R Soc Trop Med Hyg2013. 2013;107:769-76.

47. Muchie KF. Determinants of severity levels of anemia among children aged 6-59 months in Ethiopia: further analysis of the 2011Ethiopian demographic and health survey. MuchieBMC Nutrition. 2016;2(1):51.

48. Hall A, Kassa T, Demissie T, Degefie T, Lee S. National survey of the health and nutrition of schoolchildren in Ethiopia. Trop Med Int Health. 13(12):1518-26.

49. Central Statistical Agency [Ethiopia] and ICF International. Ethiopia Demographic and Health Survey 2011. Addis Ababa, Ethiopia and Calverton. Maryland: Central Statistical Agency and ICF International. p. 2005.

50. Abdi Guled R, Mamat NM, Balachew T, Bakar MA, Azdie W, Assefa N. Predictors and prevalence of anemia, among children aged 6 to 59 months in shebelle zone, Somali region, eastern Ethiopia: a cross sectional study. International Journal of Development Research. 2017;7(1):11189-96.

51. Mekasha A, Zerfu M. Prevalence of anemia among school children in Addis Ababa. Ethiop Med J. 2009;47(2):129-33.

52. Smith RE Jr. The clinical and economic burden of Anemia. Am J Manag Care. 2010;16:S59-66.

53. Alcázar $L$. The economic impact of anaemia in Peru. Lima: Group for the Analysis of Development and Action Against Hunger; 2013. Accessed at: http://www.grade.org.pe/upload/publicaciones/archivo/download/pubs/ LIBROGRADE_ANEMIAENG.pdf; accessed on: 11 Feb 2018.

54. WHO. The global prevalence of anaemia in 2011. WHO, Geneva, Switzerland, 2015. Accessed at: http://www.who.int/nutrition/publications/micronutrients/ global_prevalence_anaemia_2011/en/; Accessed date: 11 Feb 2018.

55. Soliman AT, De Sanctis V, Kalra S. Anemia and growth. Indian J Endocrinol Metab. 2014;18(Supl 1):S1-5.

56. Hurtado EK, Claussen AH, Scott KG. Early childhood anemia and mild or moderate mental retardation. Am J Clin Nutr. 1999;69:115-9.

57. Chang S, Wang L, Wang Y, Brouwer ID, Kok FJ, Lozoff B, et al. Iron-deficiency Anemia in infancy and social emotional development in preschool-aged Chinese children. Pediatrics. 2011;127:e927-e33.

58. Lozoff B, Corapci F, Burden MJ, Kaciroti N, Angulo-Barroso R, Sazawal S, et al Preschool-aged children with Iron deficiency Anemia show altered affect and behavior. J Nutr. 2007;137(3):683-9.

59. WHO. Haemoglobin concentrations for the diagnosis of anaemia and assessment of severity. Vitamin and Mineral Nutrition Information System. Geneva, World Health Organization, 2011 (WHO/NMH/NHD/MNM/11.1). 
Accessed at: (http://www.who.int/vmnis/indicators/haemoglobin.pdf; accessed date 12 Feb 2018.

60. Kassebaum NJ. The global burden of anemia. Hematology/Oncology Clinics. 2016:30(2):247-308.

61. Kassebaum NJ, Jasrasaria R, Naghavi M, Wulf SK, Johns N, Lozano R, et al. A systematic analysis of global anemia burden from 1990 to 2010. Blood. 2014;123(5):615-24.

62. Gelaye B, Kumie A, Aboset N, Berhane Y, Williams MA. School-based intervention: evaluating the role of water, latrines and hygiene education on trachoma and intestinal parasitic infections in Ethiopia. J Water Sanit Hyg Dev. 2014;4(1):120-30.

63. Zuffo CR, Osório MM, Taconeli CA, Schmidt ST, da Silva BH. CC4 a. Prevalence and risk factors of anemia in children. J Pediatr. 2016;92(4):53-60.

64. Ngesa O, Mwambi H. Prevalence and risk factors of Anaemia among children aged between 6 months and 14 years in Kenya. PLoS One. 2014;9(11):e113756.

65. Leung K-C, Johannsson G, Leong GM, HO KKY. Estrogen regulation of growth hormone action. Endocr Rev. 2004;25(5):693-721.

66. PeaceHealth Laboratory. Testosterone Testing in Females, Children and Males: Update, 2014. Accessed at: www.peacehealthlabs.org; Accessed date: 15 Feb 2018.

67. Courant F, Aksglaede L, Antignac J-P, Monteau F, Sorensen K, Andersson A-M, et al. Assessment of circulating sex steroid levels in Prepubertal and pubertal boys and girls by a novel ultrasensitive gas chromatography-tandem mass spectrometry method. J Clin Endocrinol Metab. 2010;95(1):82-92.

68. Bachman E, Travison TG, Basaria S, Davda MN, Guo W, Li M, et al. Testosterone induces Erythrocytosis via increased erythropoietin and suppressed Hepcidin: evidence for a new erythropoietin/hemoglobin set point. J Gerontol A Biol Sci Med Sci. 2014;69(6):725-35.

69. Abebe Z, Anlay DZ, Belete Biadgo, Kebede A, Melku T, Enawgaw B, et al. High prevalence of undernutrition among children in Gondar town, Northwest Ethiopia: a community-based cross-sectional study. Int J pediatr 2017; Int J Pediatr(Volume 2017):5367070.

70. Akombi BJ, Agho KE, Merom D, Renzaho AM, Hall JJ. Child malnutrition in sub-Saharan Africa: a meta-analysis of demographic and health surveys (2006-2016). PLoS One. 2017;12(5):e0177338.

71. Degarege $D$, Degarege A, Animut A. Undernutrition and associated risk factors among school age children in Addis Ababa, Ethiopia. BMC Public Health. 2015;15:375.

72. Khan JR, Awan N, Misu F. Determinants of anemia among 6-59 months aged children in Bangladesh: evidence from nationally representative data. BMC Pediatr. 2016;16:3.

73. Leite MS, Cardoso AM, Coimbra CE Jr, Welch JR, Gugelmin SA, Lira PCl, et al. Prevalence of anemia and associated factors among indigenous children in Brazil: results from the first National Survey of indigenous People's health and nutrition. Nutr J. 2013;12:69.

74. Leal LP, Filho MB, deLira PI C, Figueiroa JN, Osório MM. Prevalence of anemia and associated factors in children aged 6-59 months in Pernambuco, Northeastern Brazil. Rev Saúde Pública. 2011;45, 9(3)

75. Diaz JR, dela Scagigas A, Rodriguez R. Micronutrient deficiencies in developing and affluent countries. Eur J Clin Nutr. 2003;57(Suppl. 1):70-2.

76. Martins VJB, Toledo Florêncio TMM, Grillo LP, Franco MdCP, Martins PA, Clemente APG, et al. Long-lasting effects of undernutrition. Int J Environ Res Public Health 2011, 8, . 2011;8:1817-1846.

77. Balarajan Y, Ramakrishnan U, OÈ zaltin E, Shankar AH, Subramanian S. Anaemia in low- income and middle-income countries. Lancet. 2012;378(9809):2123-35.

78. Zanin FHC, da Silva CAM, Bonomo É, Teixeira RA, Pereira CAJ, dos Santos KB, et al. Determinants of Iron deficiency Anemia in a cohort of children aged 6-71 months living in the northeast of Minas Gerais, Brazil. PLoS One. 2015;10(10):e0139555.

Ready to submit your research? Choose BMC and benefit from:

- fast, convenient online submission

- thorough peer review by experienced researchers in your field

- rapid publication on acceptance

- support for research data, including large and complex data types

- gold Open Access which fosters wider collaboration and increased citations

- maximum visibility for your research: over $100 \mathrm{M}$ website views per year

At BMC, research is always in progress.

Learn more biomedcentral.com/submissions 